\title{
Cs retention and diffusion in C-S-H at different $\mathrm{Ca} / \mathrm{Si}$ ratios
}

\author{
Eduardo Duque-Redondo ${ }^{\dagger, *}$, Kazuo Yamada ${ }^{\ddagger}$, Iñigo López-Arbeloa ${ }^{\dagger}$ and Hegoi Manzano ${ }^{\S}$ \\ †Molecular Spectroscopy Laboratory, Department of Physical Chemistry, University of the Basque Country UPV/EHU, Aptdo. 664, 48080, Bilbao, Spain. \\ ҒFukushima Branch, National Institute for Environmental Studies, Miharu, Tamura, Fukushima, 963-7700, Japan. \\ $\S$ Department of Condensed Matter Physics, University of the Basque Country UPV/EHU, Aptdo. 664, Bilbao, Spain.
}

Cement and concrete have been widely used as a barrier to isolate many types of contaminants, including radioactive waste, in repository sites. Nevertheless, the intrusion of groundwater in those nuclear repositories may release those contaminants by leaching mechanisms. Because of this, the retention and diffusion processes in cement matrix require to be analyzed in depth. The adsorption in cement and C-S$\mathrm{H}$ gel, its main hydration product, is influenced by factors as the $\mathrm{pH}$, the composition or the alkali and alkaline earth content. In this work, molecular dynamics simulations were employed to study the role of $\mathrm{Ca} / \mathrm{Si}$ ratio of the C-S-H in the capacity to retain Cs and diffusivity of these ions in gel pores. For that purpose, we built four different C-S-H models with Ca/Si ratios from 1.1 to 2.0. The results indicate better cationic retention at low $\mathrm{Ca} / \mathrm{Si}$ ratios due to the interaction of the cations with the bridging silicate tetrahedrons. However, the average diffusion coefficients of the cations decrease at higher $\mathrm{Ca} / \mathrm{Si}$ ratios because the high ionic constraint in the nanopore that induces a longrange ordering of the water molecules.

\section{Introduction}

Nuclear power supplies the $11.5 \%$ of global electricity consumption in 2017, according to the World Nuclear Association. Nuclear energy has advantages such as low polluting emissions, the reliability or the low cost of the electricity production in comparison with other energy sources. However, nuclear power also has drawbacks; the main one is the management and final disposal of spent nuclear fuel. Not all the fission products produced in nuclear reactors are radioactive, but a significant number of them are dangerous and long-lived radioisotopes. ${ }^{137} \mathrm{Cs}$ is one of the main fission products present in spent nuclear fuel. Radiocesium is extremely harmful for humans ${ }^{1}$, highly volatile ${ }^{2}$ and constitutes the main source of radiation in the zones of alienation in Chernobyl and Fukushima ${ }^{3}$.

Cementation is a process that involves the solidification of low- and intermediate-level radioactive waste, suitable for medium- and longterm storage. Cement-based materials act as diffusion barrier, immobilizing the contaminants by adsorption and precipitation ${ }^{4,5}$. Ordinary Portland cement (OPC) is the most employed cement-type in radioactive waste cementation ${ }^{6}$, and its main hydration product, calcium silicate hydrate (C-S-H) gel, has successfully isolated the radionuclides in specific sorption and reaction sites of their surface $^{4,7}$. Even though C-S-H has an inherently low solubility and diffusibility ${ }^{8}$, there can be leaching mechanisms that may induce the potential migration of the contaminants and their release $e^{9,10}$. This reflects the importance of achieving a better understanding of the parameters that control the retention mechanisms in $\mathrm{C}-\mathrm{S}-\mathrm{H}$ and cement.

Many experimental studies have been done on Cs uptake in cement ${ }^{11-13}$. These studies highlight the impact of the experimental conditions in Cs retention. For instance, the sorption in Cs can be enhanced at $\mathrm{pH} \sim 11$, since at higher $\mathrm{pH}$ values the sorption sites of $\mathrm{C}-\mathrm{S}-\mathrm{H}$ might be saturated by the presence of a great amount of calcium hydroxide. These studies also indicate that the retention is better at low $\mathrm{Ca} / \mathrm{Si}$ ratios and when aluminum is incorporated to the C-S-H structure ${ }^{14-16}$.

In spite of there being many experimental reports about retention and dynamics of $\mathrm{CS}$ in $\mathrm{C}-\mathrm{S}-\mathrm{H}$, the molecular scale mechanism that governs those processes has not been fully determined and quantified. Molecular dynamics (MD) simulations allow to gain insight into adsorption and desorption processes at atomic level. Many researchers took $14 \AA \AA$-tobermorite as a model due to the structural resemblance to $\mathrm{C}-\mathrm{S}-\mathrm{H}^{17-19}$, in order to simplify the study of Cs retention in $\mathrm{C}-\mathrm{S}-\mathrm{H}$, both from an experimental and simulation point of view ${ }^{20-24}$. From these studies, it can be drawn that the retention mechanism is based on electrostatic sorption on the surface defects and that the interlaminar $\mathrm{Ca}$ is not exchangeable ${ }^{21}$.

In this paper, we have employed molecular dynamics simulations to study how the capability of C-S-H to retain Cs and the diffusivity of these ions are influenced by the $\mathrm{Ca} / \mathrm{Si}$ ratio. For that purpose, we built four C-S-H systems with an increasing $\mathrm{Ca} / \mathrm{Si}$ ratio, from 1.1 up to 2.0, which contains $0.26 \mathrm{Cs}$ ions per $\mathrm{C}-\mathrm{S}-\mathrm{H}$ mol. This $\mathrm{Cs}$ concentration is equivalent to a $\mathrm{Cs} / \mathrm{Ca}$ ratio of 0.85 , maximum value found experimentally in $14 \AA$-tobermorite ${ }^{23}$. The number of defects or sorption sites rises as the $\mathrm{Ca} / \mathrm{Si}$ ratio is increased, but this also implies higher content of $\mathrm{Ca}$ that can saturate those high-affinity sites. We have evaluated the competition between both mechanisms, quantifying the number and types of sorption sites, as well as the amount of $\mathrm{Ca}$ and $\mathrm{Cs}$ retained. The dynamics of these cations are also studied by means of their diffusion coefficients, exploring the impact of $\mathrm{Ca} / \mathrm{Si}$ ratio on their behavior. 


\section{Simulation details}

In order to build realistic C-S-H models we have followed the procedures reported in previous works ${ }^{16,25,26}$. The initial unit cell of $14 \AA ̊$-tobermorite ${ }^{27}$ was replicated to obtain a simulation box with dimensions of $2.6 \times 3.1 \times 3.3 \mathrm{~nm}^{3}$, corresponding to the $x, y$ and $z$ axis. The random deletion of bridging silicate groups, combined with the addition $\mathrm{Ca}$ in the interlaminar space to maintain the electroneutrality of the system, results in the increase of the $\mathrm{Ca} / \mathrm{Si}$ ratio. In this way, we were able to build $\mathrm{C}-\mathrm{S}-\mathrm{H}$ models with $\mathrm{Ca} / \mathrm{Si}$ ratios of 1.1, 1.3, 1.67 and 2.0.

We run energy minimization, followed by equilibration in the isobaric-isothermal ensemble (NPT) for $5 \mathrm{~ns}$ at $300 \mathrm{~K}$ using the ReaxFF force field ${ }^{28-30}$. This force field enables the structural, volumetric and chemical relaxation of our $\mathrm{C}-\mathrm{S}-\mathrm{H}$ models, making possible the dissociation of water molecules in dangling oxygen atoms from the new $Q^{1}$ sites of the silicate chains. After creating the bulk models with different $\mathrm{Ca} / \mathrm{Si}$ ratios, we expanded the interlaminar space to create a pore of $1 \mathrm{~nm}$ and filled it with $\mathrm{Cs}$ ions and water until reaching bulk water density. ReaxFF has not yet implemented parameters for Cs ions, so our models were transferred to traditional force fields. We employed CSHFF force field ${ }^{31}$ for the C-S-H substrate and Åqvist ${ }^{32}$ for the Cs ions. We run molecular dynamics using LAMMPS $^{33}$, using the Ewald summation method ${ }^{34}$ and the Verlet algorithm ${ }^{35}$ to compute the long-range Coulombic interactions and to integrate the motion equations, respectively. We first performed our simulations in the canonical ensemble (NVT) at $300 \mathrm{~K}$ with thermostat coupling constant of 0.1 ps during $0.5 \mathrm{~ns}$ and using a time step of $0.5 \mathrm{fs}$. The systems were further relaxed for extra $0.5 \mathrm{~ns}$ in the isobaric-isothermal ensemble (NPT) at room conditions (300K and $1 \mathrm{~atm}$ ) with a barostat coupling of 1 ps. The final pore widths are given in Table 1. A final molecular dynamics simulation is carried out in the canonical ensemble for $0.1 \mu \mathrm{s}$ at $300 \mathrm{~K}$, long enough to capture the diffusion properly.

\section{Results}

CSH models structure. The final properties of the C-S-H models at the studied $\mathrm{Ca} / \mathrm{Si}$ ratios before expanding the interlaminar space to create a $1 \mathrm{~nm}$ pore are given in Table 1, along with the final pore widths after the expansion. The values of our systems are compared with experimental and computational models reported in literature, showing good agreement. On the one hand, the agreement in the mean chain length $(\mathrm{MCL})$ and $\mathrm{C}-\mathrm{S}-\mathrm{H}$ composition $(\mathrm{H} / \mathrm{Ca}$ and $\mathrm{H} / \mathrm{Si}$ parameters) is because we have selected those values in order to replicate the experimental C-S-H systems reported in the literature. On the other hand, in our simulation the $\mathrm{Ca}-\mathrm{OH} / \mathrm{Ca}$ and $\mathrm{Si}-\mathrm{OH} / \mathrm{Si}$ parameters are given by chemical relaxation provided by ReaxFF force field. It can be seen that there is a good agreement between the values from the literature and the ones obtained in our simulations.
Table 1. Final properties for $\mathrm{C}-\mathrm{S}-\mathrm{H}$ models at $\mathrm{Ca} / \mathrm{Si}$ ratios from 1.1 to 2.0 of our simulations and from literature (values in parentheses).

\begin{tabular}{|c|c|c|c|c|}
\hline $\mathrm{Ca} / \mathrm{Si}$ & 1.1 & 1.3 & 1.67 & 2.0 \\
\hline $\mathbf{M C L}^{25,36}$ & $\begin{array}{c}5.67 \\
(5.8-6.2)\end{array}$ & $\begin{array}{c}3.0 \\
(2.9-3.3)\end{array}$ & $\begin{array}{c}2.4 \\
(2.3-2.6)\end{array}$ & $\begin{array}{c}2.2 \\
(2.1)\end{array}$ \\
\hline $\mathrm{H} / \mathrm{Ca}^{37,38}$ & $\begin{array}{c}1.7 \\
(1.7)\end{array}$ & $\begin{array}{c}2.3 \\
(2.2)\end{array}$ & $\begin{array}{c}2.5 \\
(2.4)\end{array}$ & $\begin{array}{c}2.8 \\
(2.7)\end{array}$ \\
\hline $\mathrm{Ca}-\mathrm{OH} / \mathrm{Ca}^{39,40}$ & $\begin{array}{c}0.23 \\
(0.13- \\
0.19)\end{array}$ & $\begin{array}{c}0.29 \\
(0.25- \\
0.23)\end{array}$ & $\begin{array}{c}0.37 \\
(0.44- \\
0.29)\end{array}$ & $\begin{array}{c}0.47 \\
(0.62-0.36)\end{array}$ \\
\hline $\mathrm{Si}-\mathrm{OH} / \mathrm{Si}^{42}$ & $\begin{array}{c}0.32 \\
(0.34)\end{array}$ & $\begin{array}{c}0.25 \\
(0.29)\end{array}$ & $\begin{array}{c}0.15 \\
(0.20)\end{array}$ & $\begin{array}{c}0.10 \\
(0.13)\end{array}$ \\
\hline$d_{001}(\AA)$ & 12.21 & 12.39 & 12.23 & 13.38 \\
\hline Pore width (Å) & 14.44 & 15.00 & 15.46 & 15.69 \\
\hline
\end{tabular}

Density profiles. We have computed the density profiles of our systems in order to study the distribution of the species contained in the nanopores of $\mathrm{C}-\mathrm{S}-\mathrm{H}$. The density profiles of $\mathrm{Cs}, \mathrm{Ca}$ and water molecules in C-S-H models shown in Figure 1 were obtained using a simulation trajectory of $20 \mathrm{~ns}$, averaging and normalizing the atomic positions. We have considered the Guggenheim interface convention ${ }^{42}$ in the analysis of these density profiles. Thus, it is possible to distinguish three different regions: the bulk solid region of C-S-H below the lower interfacial limit $(z=-2.5 \AA)$, the bulk liquid region of the nanopore above the upper interfacial limit $(z=0 \AA)$ and the extended interfacial region enclosed by the previous regions. In addition to the density profiles, we have also included a snapshot of the $\mathrm{C}-\mathrm{S}-\mathrm{H}$ nanopores of each analyzed system, facilitating the interpretation and comprehension.

The density profiles shown in Figure 1 reveal that water and cationic species can be located both in the extended interphase and in the bulk liquid region. The peaks under the upper interfacial limit correspond to deep-rooted species, accommodated in the cavities and structural defects of the C-S-H surface. These profiles also show strong peaks just above the upper interfacial limit for the cations due to electrostatic interactions established with the surface. Likewise, it is also possible to see strong peaks for water molecules at short distances from the upper limit, especially intense at higher $\mathrm{Ca} / \mathrm{Si}$ ratios. This may indicate an ascending hydrophilicity of the $\mathrm{C}-\mathrm{S}-\mathrm{H}$ surface as the $\mathrm{Ca} / \mathrm{Si}$ ratio increases. Besides that, there is an increasing amount of non-adsorbed $\mathrm{Cs}$ and $\mathrm{Ca}$ ions in the bulk liquid region as the $\mathrm{Ca} / \mathrm{Si}$ grows. This trend is particularly marked for $\mathrm{Ca}$ ions, since they are completely adsorbed in the C-S-H surface at low $\mathrm{Ca} / \mathrm{Si}$ ratios, but the amount of non-adsorbed $\mathrm{Ca}$ in the pore increases gradually as the $\mathrm{Ca} / \mathrm{Si}$ ratio is higher. This clearly indicates that the cation retention is worsened as the $\mathrm{Ca} / \mathrm{Si}$ ratio is increased, which can be seen in the snapshots with the naked eye. This is in the line of the findings reported by Glasser and Hong, who indicated that the retention is enhanced in $\mathrm{C}-\mathrm{S}-\mathrm{H}$ at lower $\mathrm{Ca} / \mathrm{Si}$ ratio ${ }^{43,44}$. In the following section, we quantify and discuss the cationic sorption. 

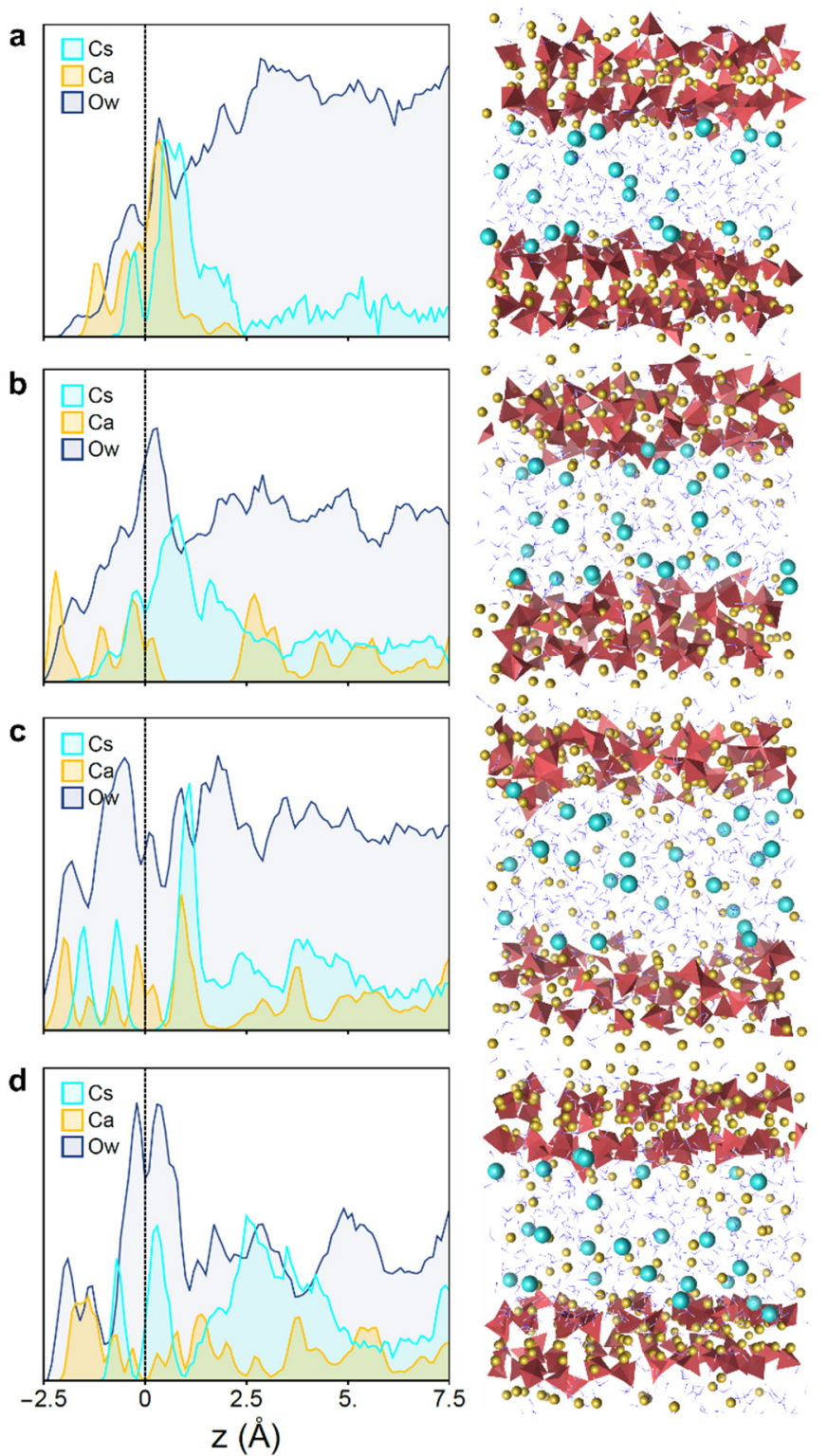

$Z(\mathrm{~A})$

Figure 1. Density profiles and their corresponding snapshots of the atomistic simulations of C-S-H at Ca/Si ratios of (a) 1.1, (b) 1.3, (c) 1.67 and (d) 2.0 with a constant Cs concentration of $0.26 \mathrm{Cs} / \mathrm{mol}$ of C-S-H. In the density profiles, the black dashed line represents the upper interfacial boundary, while the profiles of Cs, Ca and water molecules are plotted in light blue, yellow and dark blue, respectively. The garnet tetrahedrons of the snapshots correspond to silicate chains, whereas the light blue and yellow balls are the Cs and $\mathrm{Ca}$ ions. Water and hydroxyl groups are illustrated as double and simple blue sticks.

Types of adsorption sites. The partitioning resulting of the Guggenheim convention facilitates the classification of the cations according to their adsorption configurations: inner-sphere and outer-sphere adsorption. These adsorption configurations have already been reported for $\mathrm{C}-\mathrm{S}-\mathrm{H}^{26}$ and exhibit structural differences that affect to their retention capacity (See Figure 2). On the one hand, the inner-sphere sorption sites are located in the extended interfacial region, where the cations are generally trapped in cavities formed by pair and bridging silicate tetrahedrons. The interactions established between the C-S-H surface and cations adsorbed in inner-sphere sites are very strong and stable. On the other hand, the outer-sphere sorption sites are located just above the upper interfacial limit. In this configuration, the retention depends mainly on bridging silicates, so the interaction between surface and cations is not as strong as in inner-sphere sorption. Thus, the peaks of the cations in the density profiles below and above the upper interfacial limit are related to inner-sphere and outer-sphere adsorbed species, respectively. Additionally, there are other ions solvated in the $\mathrm{C}-\mathrm{S}-\mathrm{H}$ pore. Hereinafter, we will refer to the non-adsorbed cations as pore species.

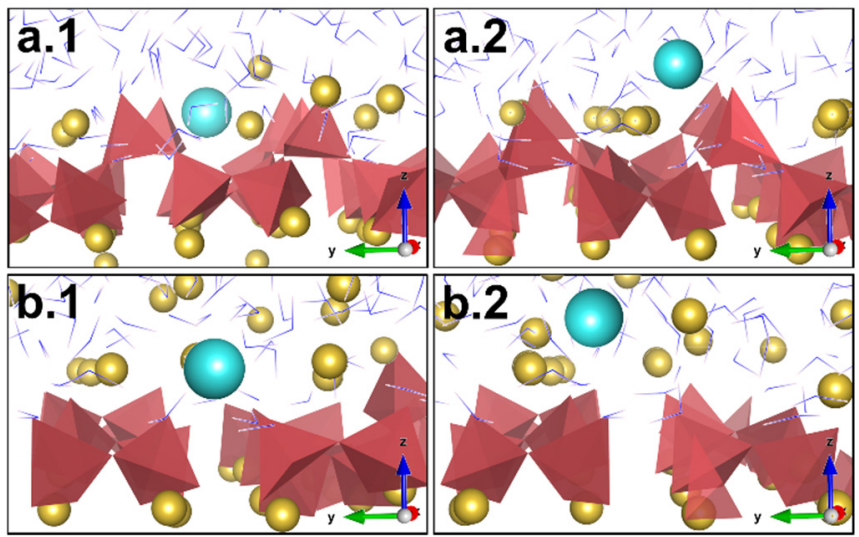

Figure 2. Snapshots of the MD simulations corresponding to the local structure of $\mathrm{Cs}$ ions adsorbed in inner-sphere sorption sites (left) and in outer-sphere sorption sites (right) in C-S-H with $\mathrm{Ca} / \mathrm{Si}$ of (a) 1.1 and (b) 2.0. The yellow and light blue balls represent intrinsic $\mathrm{Ca}$ and $\mathrm{Cs}$ ions, respectively, the garnet tetrahedrons correspond to the silicate chains and hydroxyl groups and water molecules are illustrated as simple and double blue sticks.

Since the sorption configuration may affect not only to the retention of the cations, but also to other properties such as the diffusivity, it is necessary the characterization of the type of sorption that takes place for $\mathrm{Cs}$ and $\mathrm{Ca}$. The relative amount of Cs and $\mathrm{Ca}$ adsorbed in inner-sphere and outer-sphere sorption sites is given in Table 2, as well as the number of cations solvated in the nanopore of $\mathrm{C}-\mathrm{S}-\mathrm{H}$, called pore cations.

Table 2. Percentage of cations adsorbed in inner-sphere and outersphere configurations and the pore ions in $\mathrm{C}-\mathrm{S}-\mathrm{H}$ for $\mathrm{Cs}$ and $\mathrm{Ca}$ ions. The total number of $\mathrm{Cs}$ is constant and equivalent to $0.26 \mathrm{Cs}$ per mol of $\mathrm{C}-\mathrm{S}-\mathrm{H}$ for any $\mathrm{Ca} / \mathrm{Si}$ ratio. The total number of $\mathrm{Ca}$ grows with the $\mathrm{Ca} / \mathrm{Si}$ ratio from 0.34 to $0.71 \mathrm{Ca}$ per mol of C-S-H.

\begin{tabular}{c|ccc|ccc}
\multicolumn{4}{c}{ Cs } & \multicolumn{3}{c}{ Ca } \\
\cline { 2 - 7 } $\begin{array}{c}\text { Ca/Si } \\
\text { ratio }\end{array}$ & Inner & Outer & Pore & Inner & Outer & Pore \\
\hline $\mathbf{1 . 1}$ & $16 \%$ & $49 \%$ & $35 \%$ & $36 \%$ & $64 \%$ & $0 \%$ \\
$\mathbf{1 . 3}$ & $21 \%$ & $41 \%$ & $38 \%$ & $31 \%$ & $33 \%$ & $36 \%$ \\
$\mathbf{1 . 6 7}$ & $27 \%$ & $19 \%$ & $54 \%$ & $32 \%$ & $26 \%$ & $42 \%$ \\
$\mathbf{2 . 0}$ & $31 \%$ & $4 \%$ & $65 \%$ & $33 \%$ & $7 \%$ & $60 \%$
\end{tabular}


The data from Table 2 show that the number of cations adsorbed in the two types of sorption sites decreases. This results from the reduction of the number of the high affinity sites of the surface due to the decrease of bridging silicates at higher $\mathrm{Ca} / \mathrm{Si}$ ratios. Therefore, those values indicate that the retention is enhanced at lower $\mathrm{Ca} / \mathrm{Si}$ ratios. In fact, at $\mathrm{Ca} / \mathrm{Si}$ ratio of 1.1 , there is no $\mathrm{Ca}$ dissolved in the nanopore, all $\mathrm{Ca}$ ions are adsorbed in the $\mathrm{C}-\mathrm{S}-\mathrm{H}$ surfaces. Nevertheless, the interpretation of the percentage of adsorbed and non-adsorbed $\mathrm{Ca}$ is not so easy since the amount of $\mathrm{Ca}$ in $\mathrm{C}-\mathrm{S}-\mathrm{H}$ nanopores is not constant, increases as the $\mathrm{Ca} / \mathrm{Si}$ ratio grows. For that reason, we have calculated the number of inner-sphere and outer-sphere sorption sites per area of C-S-H surface for Cs and Ca, which is independent of the ionic concentration (see Table 3).

Table 3. Number of inner/outer-sphere adsorption sites per $\mathrm{nm}^{2}$ of $\mathrm{C}-\mathrm{S}-\mathrm{H}$ and the sum of them for $\mathrm{Cs}$ and $\mathrm{Ca}$. The total number of $\mathrm{Cs}$ ions is constant and equivalent to $1.66 \mathrm{Cs}$ per $\mathrm{nm}^{2}$ of C-S-H surface for any $\mathrm{Ca} / \mathrm{Si}$ ratio. The total number of $\mathrm{Ca}$ ions increases from $2.07 \mathrm{Ca}$ per $\mathrm{nm}^{2}$ of C-S-H surface for $\mathrm{Ca} / \mathrm{Si}$ of 1.1 to 4.55 for a ratio of 2.0.

\begin{tabular}{c|ccc|ccc}
\multicolumn{1}{c}{} & \multicolumn{3}{c|}{ Cs } & \multicolumn{3}{c}{ Ca } \\
\cline { 2 - 7 } $\begin{array}{c}\text { Ca/Si } \\
\text { ratio }\end{array}$ & Inner & Outer & Sum & Inner & Outer & Sum \\
\hline $\mathbf{1 . 1}$ & 0.30 & 0.79 & $\mathbf{1 . 0 9}$ & 0.75 & 1.32 & $\mathbf{2 . 0 7}$ \\
$\mathbf{1 . 3}$ & 0.36 & 0.70 & $\mathbf{1 . 0 6}$ & 0.99 & 1.06 & $\mathbf{2 . 0 5}$ \\
$\mathbf{1 . 6 7}$ & 0.46 & 0.32 & $\mathbf{0 . 7 8}$ & 0.98 & 0.81 & $\mathbf{1 . 7 9}$ \\
$\mathbf{2 . 0}$ & 0.52 & 0.07 & $\mathbf{0 . 5 9}$ & 1.50 & 0.32 & $\mathbf{1 . 8 2}$
\end{tabular}

It can be seen that the total number of sorption sites decreases as the $\mathrm{Ca}$ /Si ratio rises for both $\mathrm{Cs}$ and $\mathrm{Ca}$ ions. However, it is remarkable that number of inner-sphere and outer-sphere sites follow opposite directions: as the $\mathrm{Ca} / \mathrm{Si}$ ratio grows, the number of inner-sphere adsorption sites increases, while the number of outer-sphere sorption sites is substantially reduced. This is due to decrease of the bridging silicate groups, the main responsible of retention in the outer-sphere configurations, facilitating the interaction of the cations with the pairing silicates.

It is also interesting that the total number of sorption sites for $\mathrm{Ca}$ remains almost constant, with a slight deviation for $\mathrm{Ca} / \mathrm{Si}$ ratio of 1.3. For $\mathrm{Ca}$, the decrease of outer-sphere sorption sites is compensated by the increase of the inner-sphere sites. This is due to the high charge density of $\mathrm{Ca}$, a divalent cation with relatively small size. In this way, $\mathrm{Ca}$ ions are able to approach closer to the surface, to innersphere sorption sites. In contrast, the moderate increase of innersphere sorption sites for Cs cannot compensate the loss of outersphere sites, since Cs has much higher size than Ca and lower charge, hindering its approach to inner-sphere sorption sites.

Diffusion coefficients. In order to avoid leaching processes of the retained cations in C-S-H it is indispensable low diffusion coefficients, aside from a good retention capacity. For that purpose, we have computed the mean square displacement (MSD) ${ }^{45}$, and through the Einstein realtionship ${ }^{46}$ we obtained the diffusion coefficient (D):

$$
D=\frac{1}{2 d} \lim _{t \rightarrow \infty} \frac{M S D}{t}
$$

where $d$ is the dimensionality of the system.

Figure 3 shows the average diffusion coefficients of water molecules and $\mathrm{Cs}$ ions as a function of the distance from the C-S-H surface. It can be seen for all the systems that the diffusion coefficients of deeprooted water are relatively low, but increase progressively until reaching the nanopore. It should be noted that the diffusion coefficient of water molecules confined in $\mathrm{C}-\mathrm{S}-\mathrm{H}$ nanopores is considerably reduced at any $\mathrm{Ca} / \mathrm{Si}$ ratio in comparison with the experimental ${ }^{47}\left(\sim 2.310^{-9} \mathrm{~m}^{2} \mathrm{~s}^{-1}\right)$ and simulated ${ }^{48}\left(\sim 2.510^{-9} \mathrm{~m}^{2} \mathrm{~s}^{-1}\right)$ values measured for bulk water. This is due to the structural and electrostatic confinement effect ${ }^{49-52}$, which provokes a reduction of the diffusion coefficients in comparison with the value in bulk water. Moreover, there is a drastic decrease of the diffusivity as the $\mathrm{Ca} / \mathrm{Si}$ ratio increases. The reasons of this decrease will be discussed in the following section.
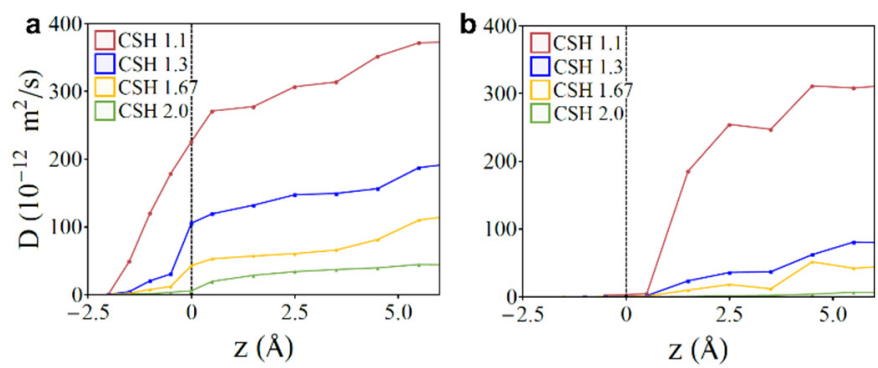

Figure 3. Evolution of the average diffusion coefficient as a function of the distance from the C-S-H surface of (a) water molecules and (b) $\mathrm{Cs}$ ions at the studied $\mathrm{Ca} / \mathrm{Si}$ ratios. The black dashed line at $\mathrm{z}=0 \AA$ represents the upper interfacial limit, while the red, blue, yellow and green lines represent the coefficients at $\mathrm{Ca} / \mathrm{Si}$ ratios of 1.1, 1.3, 1.67 and 2.0.

The diffusion coefficients of $\mathrm{Cs}$ ions are also plotted (Figure $3 \mathrm{~b}$ ) as a function of the distance from the C-S-H surface. This enables the evaluation of the diffusivity of the Cs ions adsorbed in the inner and outer-sphere configurations, as well as the non-adsorbed ones. It can be seen that the diffusion coefficients of the adsorbed Cs are almost negligible in comparison with the values of non-adsorbed Cs ions. In fact, there is a difference of two orders of magnitude in the diffusion coefficients of adsorbed and non-adsorbed Cs. Likewise, Cs ions in inner-sphere sorption sites exhibit diffusion coefficients one order of magnitude lower than in outer-sphere sites. As with water, the Cs diffusivity is strongly affected by the $\mathrm{Ca} / \mathrm{Si}$ ratio, decreasing dramatically as this ratio increases. This sharp reduction is related with the decrease of the water diffusivity. In any case, the diffusion of confined Cs is much lower than bulk water ${ }^{53}: 2.110^{-9} \mathrm{~m}^{2} \mathrm{~s}^{-1}$, up to three orders of magnitude higher than the diffusion of $\mathrm{Cs}$ in $\mathrm{C}-\mathrm{S}-\mathrm{H}$ with $\mathrm{Ca} / \mathrm{Si}$ ratio of 2.0 . 
Hydrophilic character. So far, we have found that as the $\mathrm{Ca} / \mathrm{Si}$ ratio is increased, the retention is worsened, but also the diffusion coefficients are reduced. In order to explain this apparent contradiction, it should be considered how the structural defects on the silicate chains and the cationic content affect to the dynamic of the species confined in the nanopore.

Ockwig et al. ${ }^{54}$ reported that the dynamics of confined water in the channel of clays are strongly influenced by the presence of structural defects in their silicate chains. These defects are related with the hydrophobic/hydrophilic character of clays, and can be extrapolated to $\mathrm{C}-\mathrm{S}-\mathrm{H}^{55}$ : a higher $\mathrm{Ca} / \mathrm{Si}$ ratio implies more defects in the silicate chains, increasing the number of dangling oxygen atoms and in turn increases the charge of C-S-H surfaces. This increase of acceptor groups facilitates the formation of hydrogen bonds between the surface and the water molecules, increasing the hydrophilicity of the C-S-H. In fact, this phenomenon has already been observed in the density profiles (Figure 1), which exhibit stronger peaks of water in the proximities of $\mathrm{C}-\mathrm{S}-\mathrm{H}$ surface as the $\mathrm{Ca} / \mathrm{Si}$ grows. The increase of the hydrophilicity results in constrained motion of the water molecules in the vicinities of the hydrophilic surface ${ }^{55}$. Moreover, this may induce a long-range ordering of the water molecules, reflected in stronger polarization of the water molecules in comparison with the self-polarization in bulk water ${ }^{56}$. The polarization of the pore water may contribute to create an organized hydrogen bonds network, decreasing the motion of the water molecules. In addition, it should be noted that the cations located in the nanopore, and particularly the $\mathrm{Ca}$, also facilitates the order in the interlaminar space due to their contribution to increase the ionic force that polarizes the water molecules. At higher $\mathrm{Ca} / \mathrm{Si}$ ratios there are more $\mathrm{Ca}$ ions in the nanopore, so the polarization of the water molecules increases as the $\mathrm{Ca} / \mathrm{Si}$ ratio rises. This polarization improves the ordering and decreases the diffusivity of the water molecules. In turn, the order and diffusivity of water provokes the decrease of the diffusion coefficients of the cations in the nanopore.

To check this hypothesis, we have evaluated the residence time of water molecules in the C-S-H surface (Figure 4a), the water dipolar moment (Figure $4 \mathrm{~b}$ ) and the lifetime of hydrogen bond network (Figure $4 \mathrm{C}$ ) in the nanopore at the $\mathrm{Ca} / \mathrm{Si}$ ratios under study.

The residence times of the water molecules in the C-S-H surface increases progressively as the $\mathrm{Ca} / \mathrm{Si}$ ratio becomes higher, from 0.6 ns for the lowest ratio studied to $4.7 \mathrm{~ns}$ for $\mathrm{Ca} / \mathrm{Si}$ ratio of 2.0, as it can be seen in Figure $4 a$. This indicates that the motion of those molecules is more restrained in the vicinities of the C-S-H surface as the $\mathrm{Ca} / \mathrm{Si}$ ratio grows. On the other hand, the deletion of bridging silicates at higher $\mathrm{Ca} / \mathrm{Si}$ provokes the growth of the electrostatic field in the nanopore. This originates a polarization of the water molecules, upshifting the dipole moment to larger values than the self-polarization in bulk water, as it is shown in Figure $4 \mathrm{~b}$. The dipole moment for bulk water is $2.44 \mathrm{D}$, was computed using the SPC flexible model ${ }^{57}$, but in C-S-H the dipole moment is upshift up to 2.48 $\mathrm{D}$ and $2.52 \mathrm{D}$ for $\mathrm{Ca} / \mathrm{Si}$ ratios of 1.1 and 2.0, respectively. This also confirms the intensification of the hydrophilicity of the $\mathrm{C}-\mathrm{S}-\mathrm{H}$ as $\mathrm{Ca} / \mathrm{Si}$ ratio grows. Finally, we have computed the hydrogen bond lifetime in order to prove if the polarization of the water molecules creates a stronger hydrogen bond network that causes the decrease of the diffusivity of the species in the nanopore. As can be seen in Figure 4c, the lifetime of the hydrogen bonds of water molecules confined in C$\mathrm{S}-\mathrm{H}$ is higher than in bulk water, but in turn is higher as the $\mathrm{Ca} / \mathrm{Si}$ ratio rises. Thus, the half-life of the hydrogen bonds in bulk water is $40 \mathrm{ps}$. This value increases up to $44 \mathrm{ps}$ for hydrogen bonds in $\mathrm{C}-\mathrm{S}-\mathrm{H}$ with a $\mathrm{Ca} / \mathrm{Si}$ ratio of 1.1 , and reaches $60 \mathrm{ps}$ at $\mathrm{Ca} / \mathrm{Si}$ ratios of 2.0. This enhanced hydrogen bond network restrains the motion of the water molecules, and also reduces the diffusivity of the cations dissolved in the nanopore.
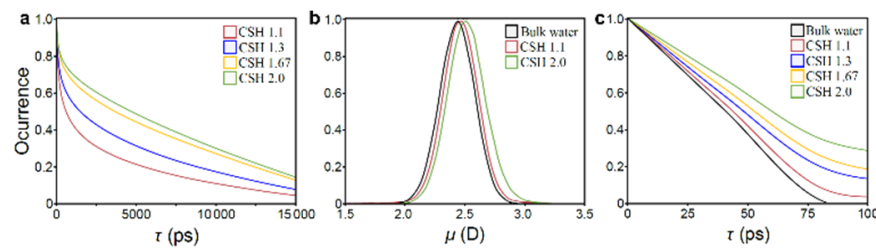

Figure 4. (a) Autocorrelation functions of water-surface oxygen atoms for the $\mathrm{C}-\mathrm{S}-\mathrm{H}$ at the studied $\mathrm{Ca} / \mathrm{Si}$ ratios. (b) Water dipole moment in bulk water, $\mathrm{C}-\mathrm{S}-\mathrm{H}$ with $\mathrm{Ca} / \mathrm{Si}$ ratio of 1.1 and 2.0. (c) Hydrogen bond lifetimes for bulk water and water confined in $\mathrm{C}-\mathrm{S}-\mathrm{H}$ at the studied $\mathrm{Ca} / \mathrm{Si}$ ratios. Red, blue, yellow and green lines correspond to the $\mathrm{C}-\mathrm{S}-\mathrm{H}$ systems with $\mathrm{Ca} / \mathrm{Si}$ ratios of $1.1,1.3,1.67$ and 2.0, respectively, whereas the black line is referred to bulk water.

\section{Conclusions}

In this work, we have explored the role of the $\mathrm{Ca} / \mathrm{Si}$ ratio in the retention and diffusivity of $\mathrm{Cs}$ confined in a C-S-H nanopore of $1 \mathrm{~nm}$ at constant $\mathrm{Cs}$ concentration, $0.26 \mathrm{Cs} / \mathrm{mol}$ of $\mathrm{C}-\mathrm{S}-\mathrm{H}$. For that reason, we have developed four $\mathrm{C}-\mathrm{S}-\mathrm{H}$ models with $\mathrm{Ca} / \mathrm{Si}$ ratios ranging from 1.1 to 2.0. We have studied the distribution of the Cs and intrinsic $\mathrm{Ca}$ in the pore, the type of adsorption for both cations, the number of high affinity sites in the C-S-H surface and diffusivity of those cations under different $\mathrm{Ca} / \mathrm{Si}$ ratios.

The analysis of the arrangement of the species located in the nanopore shows that as the $\mathrm{Ca} / \mathrm{Si}$ is increased, there are more cations dissolved in the $\mathrm{C}-\mathrm{S}-\mathrm{H}$ nanopores. In fact, the number of $\mathrm{Cs}$ desorbed at $\mathrm{Ca} / \mathrm{Si}$ ratio of 2.0 is almost twice than at a ratio of 1.1. The type of adsorption is also modified at different $\mathrm{Ca} / \mathrm{Si}$ ratios. As the $\mathrm{Ca} / \mathrm{Si}$ ratio is increased, the silicate chains are shorten by deletion of bridging silicate groups, making the pairing silicate groups more accessible to the cations. Thus, the number of outer-sphere adsorption sites, which involve preferably bridging silicates, decreases, while it is increased the number of inner-sphere adsorption sites, based basically on the pairing silicates. Nevertheless, the increase of inner-sphere adsorption sites does not compensate the loss of outer-sphere ones, so the total number of high affinity sites in the $\mathrm{C}-\mathrm{S}-\mathrm{H}$ surface is reduced at almost half of the total at low $\mathrm{Ca} / \mathrm{Si}$ ratios. 
The study of dynamics of the species located in the nanopore shows that their diffusivity is progressively reduced as the $\mathrm{Ca} / \mathrm{Si}$ ratio rises. For Cs ions, the reduction of its diffusion coefficient is over $90 \%$ for the $\mathrm{C}-\mathrm{S}-\mathrm{H}$ with the highest $\mathrm{Ca} / \mathrm{Si}$ ratio studied with respect to the one with the lowest ratio. The increase of the hydrophilicity of the $\mathrm{C}-\mathrm{S}-\mathrm{H}$ nanopore as the $\mathrm{Ca} / \mathrm{Si}$ ratio grows is the main responsible of the decrease of water diffusivity. The higher number of dangling oxygen atoms in the $\mathrm{C}-\mathrm{S}-\mathrm{H}$ surface at higher $\mathrm{Ca} / \mathrm{Si}$ ratios, facilitates the formation of hydrogen bonds between the surface and the pore water. This reduces the mobility of the water molecules in the vicinities and induces a long-range ordering, polarizing the water molecules and reducing the global diffusion coefficients. Likewise, the cations, especially $\mathrm{Ca}$ ions, whose content grows at higher $\mathrm{Ca} / \mathrm{Si}$ ratios, also contribute to increase the electrostatic field that polarizes the water molecules and enhances the hydrogen bond network. Thus, the motion of the water molecules is hindered, and consequently it hinders the motion of the cations solvated in the pore. Therefore, despite having much worse retention at high $\mathrm{Ca} / \mathrm{Si}$ ratios, the diffusion coefficients of $\mathrm{Cs}$ ions in the nanopore decrease. Nevertheless, in order to prevent the released of Cs confined in C-S$\mathrm{H}$ nanopores, is essential strong retention in the sorption sites rather than low diffusivity in the pore.

\section{Author information}

*E-mail: eduardo.duque@ehu.eus

\section{Acknowledgements}

This work was supported by "Departamento de Educación, Política Lingüística y Cultura del Gobierno Vasco" (IT912-16) and the ELKARTEK program. E.D.-R. acknowledge the "Contrato de Personal Investigador Predoctoral en Formación" from the UPV/EHU, respectively. The authors thank for technical and human support provided by IZO-SGI SGIker of UPV/EHU and European funding (ERDF and ESF), as well as the i2 basque computing resources.

\section{References}

1 A. T. Ramalho and A. C. H. Nascimento, Health Phys., 1991, 60, 67-70.

2 M. Jantunen, A. Reponen, P. Kauranen and M. Vartiainen, Health Phys., 1991, 60, 427-434.

3 A. Real, S. Sundell-Bergman, J. F. Knowles, D. S. Woodhead and I. Zinger, J. Radiol. Prot., 2004, 24, A123-A137. J. Real, F. Persin and C. Camarasa-Claret, J. Environ. Radioact., 2002, 62, 1-15.

5 F. Macášek, in Natural Microporous Materials in Environmental Technology, Springer, 1999, pp. 109-135.

6 F. P. Glasser and M. Atkins, MRS Bull., 1994, 19, 33-38.

7 K. Volchek, M. Y. Miah, W. Kuang, Z. DeMaleki and F. H. Tezel, J. Hazard. Mater., 2011, 194, 331-337.

8 P. Hewlett, Lea's chemistry of cement and concrete, Butterworth-Heinemann, 2003.

9 T. M. Krishnamoorthy, S. N. Joshi, G. R. Doshi and R. N. Nair, Nucl. Technol., 1993, 104, 351-357.
K. G. Papadokostaki and A. Savidou, J. Hazard. Mater., 2009, 171, 1024-1031.

C. Shi and A. Fernandez-Jimenez, J. Hazard. Mater., 2006, 137, 1656-1663.

N. D. M. Evans, Cem. Concr. Res., 2008, 38, 543-553.

R. W. Crawford, C. McCulloch, M. Angus, F. P. Glasser and A. A. Rahman, Cem. Concr. Res., 1984, 14, 595-599.

M. Ochs, D. Mallants and L. Wang, Radionuclide and Metal Sorption on Cement and Concrete, Springer International Publishing, 2015.

S. Bagosi and L. J. Csetényi, Cem. Concr. Res., 1998, 28, 1753-1759.

E. Duque-Redondo, K. Yamada, I. L. Arbeloa and H. Manzano, 2018.

H. F. W. Taylor, J. Am. Ceram. Soc., 1986, 69, 464-467.

I. G. Richardson, Cem. Concr. Compos., 2000, 22, 97-113.

L. B. Skinner, S. R. Chae, C. J. Benmore, H. R. Wenk and P. J. M. Monteiro, Phys. Rev. Lett., 2010, 104, 195502_11955024.

M. Tsuji, S. Komarneni and P. Malla, J. Am. Ceram. Soc., 1991, 74, 274-279.

S. Komarneni, D. Roy, C. Fyfe and G. Kennedy, Cem. Concr. Res., 1987, 17, 891-895.

S. Komarneni and M. Tsuji, J. Am. Ceram. Soc., 1989, 72, 1668-1674.

M. Miyake, S. Komarneni and R. Roy, Mater. Res. Bull., 1989, 24, 311-320.

J. Jiang, P. Wang and D. Hou, Phys. Chem. Chem. Phys., 2017, 27974-27986.

M. J. Abdolhosseini Qomi, K. J. Krakowiak, M. Bauchy, K. L. Stewart, R. Shahsavari, D. Jagannathan, D. B. Brommer, A. Baronnet, M. J. Buehler, S. Yip, F.-J. Ulm, K. J. Van Vliet and R. J. M. Pellenq, Nat Commun, 2014, 5, 1-10.

E. Duque-Redondo, K. Yamada, I. López-Arbeloa, H. Manzano, E. D. REDONDO, Y. Kazuo, I. López-Arbeloa and H. Manzano, Phys. Chem. Chem. Phys., 2018, (In press).

E. Bonaccorsi, S. Merlino and A. R. Kampf, J. Am. Ceram. Soc., 2005, 88, 505-512.

K. Chenoweth, A. C. T. van Duin and W. A. Goddard, J. Phys. Chem. A, 2008, 112, 1040-1053.

J. C. Fogarty, H. M. Aktulga, A. Y. Grama, A. C. T. van Duin and S. A. Pandit, J. Chem. Phys., 2010, 132, 174704_1174704_10.

H. Manzano, R. J. M. Pellenq, F.-J. Ulm, M. J. Buehler and A. C. T. van Duin, Langmuir, 2012, 28, 4187-4197.

R. Shahsavari, R. J.-M. Pellenq and F.-J. Ulm, Phys. Chem. Chem. Phys., 2011, 13, 1002-1011.

J. Åqvist, J. Phys. Chem., 1990, 94, 8021-8024.

S. Plimpton, J. Comput. Phys., 1995, 117, 1-19.

P. P. Ewald, Ann. Phys., 1921, 369, 253-287.

L. Verlet, Phys. Rev., 1967, 159, 98-103.

J. J. Chen, J. J. Thomas, H. F. W. Taylor and H. M. Jennings, Cem. Concr. Res., 2004, 34, 1499-1519.

K. Fujii and W. Kondo, J. Chem. Soc. Dalt. Trans., 1981, 645651.

X. D. Cong and R. J. Kirkpatrick, J. Am. Ceram. Soc., 1996, 79, 1585-1592.

J. Thomas, J. J. Chen, H. M. Jennings and D. A. Neumann Chem. Mater., 2003, 15, 3813-3817.

J. S. Dolado, M. Griebel and J. Hamaekers, J. Am. Ceram. Soc., 2007, 90, 3938-3942.

X. Cong and R. J. Kirkpatrick, Adv. Cem. Based Mater., 1996, 
3, 144-156.

42 E. A. Guggenheim, Thermodynamics-an advanced treatment for chemists and physicists, 1985. F. P. Glasser, in MRS Proceedings, Cambridge Univ Press, 2002, vol. 713, pp. 721-732.

44 S.-Y. Hong and F. P. Glasser, Cem. Concr. Res., 1999, 29, 1893-1903.

45 M. Brehm and B. Kirchner, J. Chem. Inf. Model., 2011, 51, 2007-2023.

46 A. Einstein, Ann. Phys., 1905, 322, 549-560.

47 K. Krynicki, C. D. Green and D. W. Sawyer, Faraday Discuss. Chem. Soc., 1978, 66, 199-208.

48 M. W. Mahoney and W. L. Jorgensen, J. Chem. Phys., 2001, 114, 363-366.

49 A. G. Kalinichev, J. W. Wang and R. J. Kirkpatrick, Cem. Concr. Res., 2007, 37, 337-347.

50 H. Manzano, S. Moeini, F. Marinelli, A. C. T. van Duin, F.-J. Ulm and R. J. M. Pellenq, J. Am. Chem. Soc., 2012, 134, 2208-2215.

51 M. J. A. Qomi, M. Bauchy, F.-J. Ulm and R. J.-M. Pellenq, J. Chem. Phys., 2014, 140, 054515_1-054515_11.

P. A. Bonnaud, H. Manzano, R. Miura, A. Suzuki, N. Miyamoto, N. Hatakeyama and A. Miyamoto, J. Phys. Chem. C, 2016, 120, 11465-11480.

L. Yuan-Hui and S. Gregory, Geochim. Cosmochim. Acta, 1974, 38, 703-714.

54 N. W. Ockwig, J. A. Greathouse, J. S. Durkin, R. T. Cygan, L. L. Daemen and T. M. Nenoff, J. Am. Chem. Soc., 2009, 131, 8155-8162.

55 M. Youssef, R. J. M. Pellenq and B. Yildiz, J. Am. Chem. Soc., 2011, 133, 2499-2510.

56 F. Coudert, R. Vuilleumier and A. Boutin, ChemPhysChem, 2006, 7, 2464-2467.

57 H. J. C. Berendsen, J. P. M. Postma, W. F. van Gunsteren and J. Hermans, in Intermolecular forces, Springer, 1981, pp. 331-342. 